\title{
Effect of nursery on asthma and acute upper respiratory infection in healthy preschool children
}

\author{
Chunchou Luo ${ }^{1}$, Yanzhen Yang ${ }^{1}$, Peiling $\mathrm{Li}^{1}$, Xiangui Chen ${ }^{1}$, Mengyun Cai ${ }^{1}$, Yijun Wang ${ }^{2}$
}

'Department of Pediatrics, Zhangzhou Municipal Hospital Affiliated to Fujian Medical University, Xiangcheng District, Zhangzhou City, Fujian, China

2Department of Oncology, Zhangzhou Municipal Hospital Affiliated to Fujian Medical University, Xiangcheng District, Zhangzhou City, Fujian, China

Adv Dermatol Allergol 2022; XXXIX (4): 675-681

DOI: https://doi.org/10.5114/ada.2021.108420

\begin{abstract}
Aim: The aim of the study was to investigate the effect of admission to nursery on the incidence of acute upper respiratory infection (AURI) in healthy preschool children, analyse the aetiology of AURI, and provide reference for its clinical diagnosis and treatment.

Material and methods: Pharyngeal swab samples were dynamically collected from 119 healthy preschool children who were first time admitted to a local public nursery for multiple etiological detection to explore the time of the first occurrence of AURI after admission to the nursery and the causes of infection. The effect of nursery on pathogen colonization in the pharynx in preschool children was also analysed.

Results: A total of 91 children developed AURI in the nursery. There was a significant difference between genders $\left(\chi^{2}=4.078, p=0.043\right)$. The common pathogens of AURI showed a concentrated distribution. The proportions of bacterial, mycoplasma, and viral infections were $51.65 \%, 15.38 \%$, and $12.09 \%$, respectively, of which the proportions of mixed infection of two bacteria and mixed infection of bacteria and non-bacteria were $5.50 \%$ and $5.50 \%$, respectively. A total of 28 children did not develop AURI in the nursery. There was no significant difference in the number of pathogens in the pharynx between the results before and after admission to the nursery $(t=0.700, p=0.488)$. Conclusions: Collective living in the nursery causes a concentrated incidence of AURI in preschool children and has no effect on pathogen colonization in the pharynx in uninfected children. Bacteria are the main pathogen of AURI. The health education of children in nurseries needs to be strengthened to avoid the cross-infection in the population.
\end{abstract}

Key words: acute upper respiratory infection, nursery.

\section{Introduction}

Acute upper respiratory infection (AURI) is the most common disease in children, caused by single or mixed infections with a variety of pathogens, including bacteria, viruses, mycoplasma, and chlamydia [1-3]. Because pathogens can be transmitted by droplet or direct contact, environmental factors are closely related to the incidence of AURI. Children are infected during their collective life in nurseries, resulting in cross-transmission of pathogens in different communities. Due to the size of each class or group the children are facing infected patients and because they are more disposed to asthma and infectious disease, they are in the high-risk situation. Therefore, the difficulty of epidemiological investigation and clinical diagnosis and treatment is increased [4-6].

\section{Aim}

In this study, throat swab samples were dynamically collected from healthy preschool children who were first admitted to nursery for multiple aetiology detection. The effect of admission of the nursery on the incidence of AURI in children was explored to provide reference for disease prevention and standardized diagnosis and treatment.

Address for correspondence: Yijun Wang, Department of Oncology, Zhangzhou Municipal Hospital Affiliated to Fujian Medical University, 59 Shengli West Road, Xiangcheng District, Zhangzhou City, Fujian 363000, China, e-mail: dr.yijunw@gmail.com Received: 16.04.2021, accepted: 7.05.2021. 


\section{Material and methods}

\section{Subjects}

A total of 131 healthy preschool children, as screening subjects, were first admitted to a local public nursery after random computer allocation by the municipal education bureau. Their guardians were informed and signed the consent.

Inclusion criteria: (1) no fever, nasal discharge, pharyngalgia, cough and other symptoms of the upper respiratory infection; (2) no anti-infective drugs against bacteria, viruses were used within 1 week; (3) no other acute and chronic diseases including dyspepsia, rickets, primary immunodeficiency disease [1].

Finally, 119 children were included, with 58 boys and 61 girls, aged from 2 years and 11 months to 3 years and 10 months. This study was approved by the Medical Ethics Committee of the Zhangzhou Municipal Hospital Affiliated to Fujian Medical University (2017-LW-020).

\section{Diagnostic criteria for AURI}

AURI is a general term, covering acute inflammation of the nasal cavity, pharynx, or larynx. Its symptoms are as follows: 1) common cold is characterized by nasopharyngeal catarrh, with sneezing, nasal obstruction, and watery nasal discharge; 2) acute pharyngitis is characterized by pharynx dryness, burning sensation, pharyngalgia; 3) acute tonsillitis is characterized by pharyngalgia, fever, dysphagia. AURI can also be accompanied by varying degrees of systemic symptoms, such as muscle pain, headache, chill, sweating and fatigue [7].

\section{Collection of throat swab samples}

The first sampling time was when the children gathered for physical examination before admission to the nursery; the samples of the infected children were collected when AURI first occurred $48 \mathrm{~h}$ after admission; the samples of the uninfected children throughout the semester were collected when they gathered before the holiday.

Before collection, the oral cavity of the children was cleaned with normal saline. After the tongue depressor gently pressed the tongue, the secretion of the posterior pharynx wall was immediately wiped with a sterile swab from left to right twice. And then the swabs were placed in sample collection tubes, and submitted for examination immediately.

\section{Aetiology detection}

The samples were incubated in blood agar and chocolate culture dish, respectively, and placed in the incubator $\left(5 \% \mathrm{CO}_{2}, 35^{\circ} \mathrm{C}\right)$ for $18-24 \mathrm{~h}$ to observe whether there was bacterial growth. The bacteria were semi-quantitatively analysed by sectional streak, and 3+, 2+, and 1+ indicated a large, moderate, and small number of bacteria, respectively [8].
Fluorescently labelling monoclonal antibodies of the respiratory virus were used to detect seven viral antigens, including respiratory syncytial virus (RSV), adenovirus (ADV), influenza virus type A (Iva), type B (Ivb), parainfluenza virus type I (PIV I), type II (PIV II) and type III (PIV III). PCR-fluorescence probe was used for quantitative detection of mycoplasma pneumoniae and chlamydia DNA, and the kit was obtained from DaAn Gene Co., Ltd. The specific operation process was based on the instructions of the manufacturer of the reagent and the kit.

\section{Bacterial identification and drug sensitivity test}

Bacterial strains with $2+$ or above were identified using VITEK-2 Compact automatic bacterial identification and drug sensitivity analysis system (bioMerieux, France). Drug sensitivity tests were performed according to the recommended method of the Clinical and Laboratory Standards Institute (CLSI) in 2015 [9].

\section{Quality control}

The sample collection personnel were paediatric nurses working in our hospital for more than 5 years, who had received unified training and passed the assessment. According to the standard collection method of throat swab samples [5], the children had oral care carried out before collection to ensure oral cleanliness. If the sterile swab touched the oral mucosa or tongue during collection, it was considered contaminated and re-collected.

\section{Statistical analysis}

SPSS 18.0 statistical software was used for statistical analysis. The $t$ test was used for comparison of measurement data, while for the comparison of enumeration data the $\chi^{2}$ test or continuity correction $\chi^{2}$ test was used. $P<0.05$ was considered statistically significant.

This study was approved by the Medical Ethics Committee of the Zhangzhou Municipal Hospital Affiliated to Fujian Medical University (2017-LW-020).

\section{Results}

Population distribution of 91 children with AURI in the nursery

The incidence of AURI during the semester was $76.47 \%$ (91/119). There was no significant difference in the incidence between different gender groups and different age groups (Table 1).

\section{Time distribution of 91 children with AURI in nursery}

This study was started in August 2017, and the sample collection was completed in January 2018. It can be seen that there was incidence from August to December, with 
Table 1. Population distribution of 91 children with AURI during nursery attendance

\begin{tabular}{|c|c|c|c|c|c|}
\hline Group & Number of cases & Total population & Incidence & $\chi^{2}$ & $P$-value \\
\hline \multicolumn{6}{|l|}{ Gender: } \\
\hline Boy & 45 & 58 & $77.59 \%$ & 0.078 & 0.780 \\
\hline Girl & 46 & 61 & $75.41 \%$ & & \\
\hline \multicolumn{6}{|l|}{ Age: } \\
\hline 2 years and 11 months -3 years and 1 month & 24 & 29 & $82.76 \%$ & 1.642 & 0.650 \\
\hline 3 years and 2 months -3 years and 4 months & 23 & 33 & $69.70 \%$ & & \\
\hline 3 years and 5 months -3 years and 7 months & 23 & 29 & $79.31 \%$ & & \\
\hline 3 years and 8 months -3 years and 10 months & 21 & 28 & $75.00 \%$ & & \\
\hline
\end{tabular}

the highest incidence of $34.07 \%$ in October (Figure 1). The first occurrence of AURI in children was fastest at 15 days and slowest at 119 days after admission to the nursery. In terms of time of the first occurrence, there was a significant difference between genders $\left(\chi^{2}=3.501\right.$, $p=0.0478)$, with boys slightly earlier than girls, while there was no significant difference among age groups $\left(\chi^{2}=9.897, p=0.738\right)$ (Table 2).

Further analysis showed that 61 children were infected with common pathogens. According to monthly statistics (Table 3), streptococcus pneumoniae and staphylococcus aureus infections mainly occurred in October to November; haemophilus influenzae and streptococcus haemolyticus B were mainly in November to December; influenza virus A was mainly in November; adenovirus occurred only in December. The children were mainly infected with mycoplasma in August to September. The common pathogens causing AURI in children during the semester showed a concentrated distribution. There was no significant difference in the distribution of common pathogens among different months $\left(\chi^{2}=31.922, p=\right.$ 0.586).

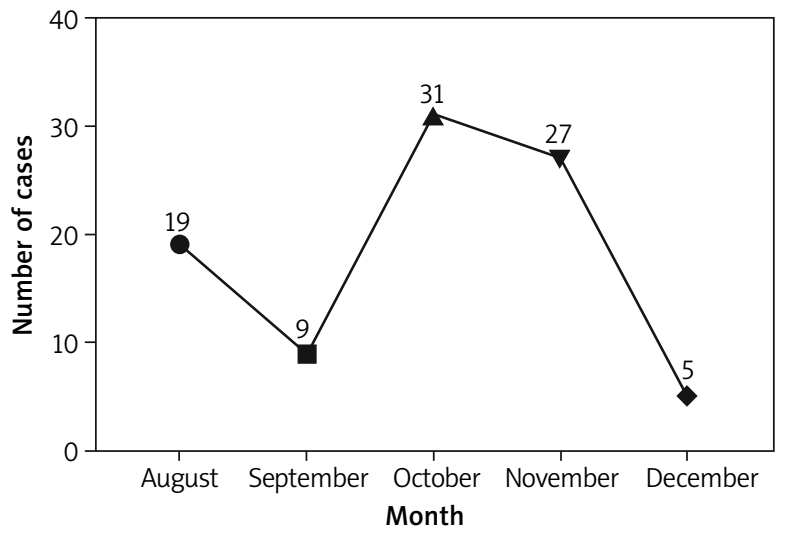

Figure 1. Time distribution of the first occurrence of AURI in nursery

\section{Etiological analysis of AURI and distribution of common pathogens}

With reference to the clinical judgment standard, the result of $2+$ and above was considered as dominant bacteria or pathogenic bacteria, while $1+$ or less was consid-

Table 2. Distribution of the first occurrence of AURI in different genders and ages

\begin{tabular}{|c|c|c|c|c|c|c|c|c|}
\hline \multirow[t]{2}{*}{ Group } & \multicolumn{6}{|c|}{ First occurrence of AURI } & \multirow[t]{2}{*}{$\chi^{2}$} & \multirow[t]{2}{*}{$P$-value } \\
\hline & August & September & October & November & December & Total & & \\
\hline \multicolumn{9}{|l|}{ Gender: } \\
\hline Boy & 12 & 5 & 15 & 10 & 3 & 45 & \multirow[t]{2}{*}{$3.501^{*}$} & \multirow[t]{2}{*}{0.0478} \\
\hline Girl & 7 & 4 & 16 & 17 & 2 & 46 & & \\
\hline \multicolumn{9}{|l|}{ Age: } \\
\hline 2 years and 11 months -3 years and 1 month & 5 & 1 & 10 & 8 & 0 & 24 & \multirow{4}{*}{$9.897^{*}$} & \multirow[t]{4}{*}{0.738} \\
\hline 3 years and 2 months -3 years and 4 months & 5 & 2 & 8 & 7 & 1 & 23 & & \\
\hline 3 years and 5 months -3 years and 7 months & 4 & 3 & 5 & 9 & 2 & 23 & & \\
\hline 3 years and 8 months -3 years and 10 months & 5 & 3 & 8 & 3 & 2 & 21 & & \\
\hline Total & 19 & 9 & 31 & 27 & 5 & 91 & / & / \\
\hline
\end{tabular}

${ }^{\star}$ A continuity correction $\chi^{2}$ test was applied. 
Table 3. Distribution of common pathogens in different months

\begin{tabular}{lccccccc}
\hline \multirow{2}{*}{ Pathogen } & \multicolumn{4}{c}{ Number of positive cases in different months $(n)$} & \multicolumn{2}{c}{ Total } \\
\cline { 2 - 7 } & August & September & October & November & December & January & \\
\hline Streptococcus pneumoniae & 0 & 2 & 3 & 4 & 1 & 0 & 10 \\
\hline Haemophilus influenzae & 0 & 1 & 1 & 5 & 3 & 0 & 10 \\
\hline Staphylococcus aureus & 0 & 1 & 4 & 3 & 1 & 0 & 9 \\
\hline Streptococcus haemolyticus B & 0 & 0 & 0 & 4 & 3 & 0 & 7 \\
\hline Mycoplasma & 1 & 3 & 2 & 6 & 2 & 0 & 14 \\
\hline Influenza A & 0 & 0 & 0 & 4 & 1 & 0 & 5 \\
\hline Influenza B & 0 & 0 & 1 & 0 & 1 & 0 & 2 \\
\hline Parainfluenza virus type I & 0 & 0 & 0 & 1 & 1 & 0 & 2 \\
\hline Adenovirus & 0 & 0 & 0 & 0 & 2 & 0 & 2 \\
\hline Total & 1 & 7 & 11 & 27 & 15 & 0 & 61 \\
\hline
\end{tabular}

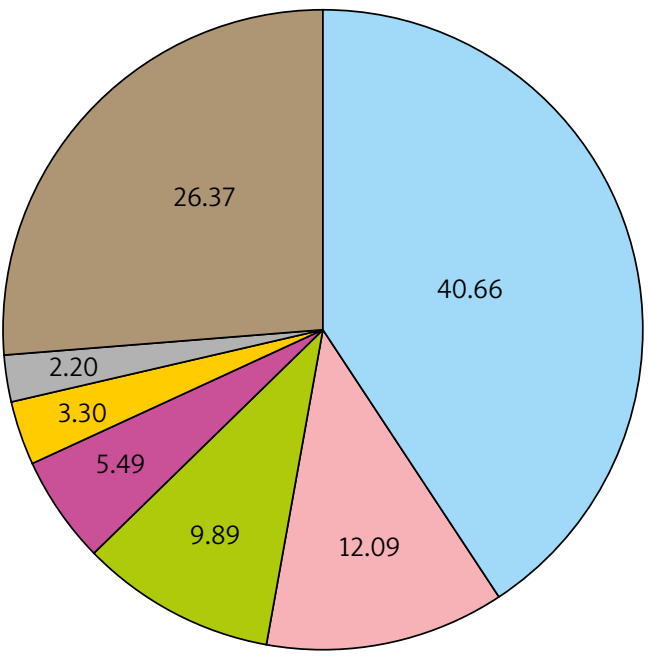

$\square$ One bacterial infection

$\square$ Mycoplasma infection

$\square$ Viral infection

$\square$ Mixed infection of two kinds of bacteria

$\square$ Mixed infection of bacteria and mycoplasma

$\square$ Mixed infection of bacteria and virus

$\square$ The reason is unknown

Figure 2. Distribution of different causes of AURI in 91 children

ered as non-dominant bacteria or contaminated bacteria in semi-quantitative analysis of bacterial culture identification. In the first occurrence of AURI in 91 children, 47 children had 52 strains of new bacteria (including 1 fungus) with $2+$ or more, as bacterial (including fungus) infections (Figure 2); 14 children had positive mycoplasma PCR results and 11 children had positive viral antibodies, as non-bacterial infections. Among the in-

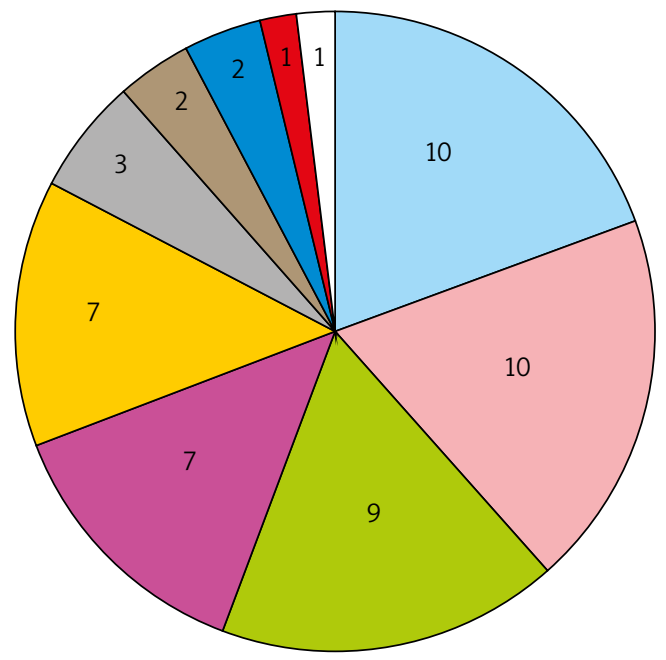

$\square$ Streptococcus pneumonia

$\square$ Haemophilus influenza

$\square$ Staphylococcus aureus

$\square$ Streptococcus haemolyticus B

$\square$ Streptococcus vulgaris

$\square$ Catamola

$\square$ Escherichia coli

- Coagulase negative Staphylococcus

- Streptococcus pyogenes

$\square$ Candida glabrata

Figure 3. The proportion of dominant bacteria in throat swab culture of AURI children

fected children, 5 children had mixed infection of two kinds of bacteria and 5 children had mixed infection of the bacteria and virus. The proportion of different causes was mainly shown in Figure 3. In addition, new bacteria with $2+$ or more were not detected in the remaining 24 children. There was no significant difference in patho- 
Table 4. Distribution of common pathogens in different genders and ages

\begin{tabular}{|c|c|c|c|c|c|c|}
\hline \multirow[t]{2}{*}{ Pathogen } & \multicolumn{2}{|c|}{ Gender } & \multicolumn{4}{|c|}{ Age } \\
\hline & Boy & Girl & $\begin{array}{c}2 \text { years and } \\
11 \text { months }-3 \text { years } \\
\text { and } 1 \text { months }\end{array}$ & $\begin{array}{c}3 \text { years and } \\
2 \text { months }-3 \text { years } \\
\text { and } 4 \text { months }\end{array}$ & $\begin{array}{c}3 \text { years and } \\
5 \text { months }-3 \text { years } \\
\text { and } 7 \text { months }\end{array}$ & $\begin{array}{c}3 \text { years and } \\
8 \text { months }-3 \text { years } \\
\text { and } 10 \text { months }\end{array}$ \\
\hline Streptococcus pneumoniae & 6 & 4 & 5 & 1 & 2 & 2 \\
\hline Haemophilus influenzae & 6 & 4 & 2 & 4 & 2 & 2 \\
\hline Staphylococcus aureus & 7 & 2 & 3 & 2 & 2 & 2 \\
\hline Streptococcus haemolyticus B & 1 & 6 & 2 & 2 & 2 & 1 \\
\hline Streptococcus viridis & 2 & 5 & 0 & 3 & 4 & 0 \\
\hline Moraxella catarrhalis & 2 & 1 & 1 & 1 & 1 & 0 \\
\hline Escherichia coli & 1 & 1 & 1 & 1 & 0 & 0 \\
\hline Coagulase negative Staphylococcus & 1 & 1 & 0 & 2 & 0 & 0 \\
\hline Streptococcus pyogenes & 0 & 1 & 0 & 0 & 0 & 1 \\
\hline Candida glabrata & 1 & 0 & 0 & 1 & 0 & 0 \\
\hline Mycoplasma & 4 & 10 & 2 & 4 & 5 & 3 \\
\hline Influenza A & 1 & 4 & 0 & 1 & 1 & 3 \\
\hline Influenza B & 2 & 0 & 2 & 0 & 0 & 0 \\
\hline Parainfluenza virus & 0 & 2 & 2 & 0 & 0 & 0 \\
\hline \multirow[t]{2}{*}{ Adenovirus } & 1 & 1 & 0 & 1 & 1 & 0 \\
\hline & 35 & 42 & 20 & 23 & 20 & 14 \\
\hline$\chi^{2}$ & \multicolumn{2}{|c|}{18.016} & \multicolumn{4}{|c|}{36.792} \\
\hline$P$-value & \multicolumn{2}{|c|}{0.125} & \multicolumn{4}{|c|}{0.575} \\
\hline
\end{tabular}

gen infection between the genders and no significant difference among ages ( $p>0.05$ ) (Table 4). If virus, mycoplasma and chlamydia were negative and the cause of infection could not be accurately determined, the possibility of bacterial colonization or false negative was considered.

\section{Comparison of 28 children without AURI before and after pathogen colonization in the pharynx}

Twenty-eight children did not develop AURI throughout the semester, and their samples were collected again at the end of the semester. Eighty-seven strains of bacteria were isolated from the throat swabs, with an average of $3.63 \pm 0.49$ strains, while there was an average of $3.50 \pm 0.72$ strains before admission to the nursery. There was no significant difference between the two results $(t=1.037, p=0.304)$. One child with positive mycoplasma before entering the nursery and 2 children with positive mycoplasma at the end of the semester, there was no significant difference $\left(\chi^{2}=356, p=1.000\right)$.

\section{Discussion}

The incidence of AURI ranks first among all kinds of paediatric diseases in China. Preschool children have poor environmental adaptability and weak awareness of self-protection, coupled with the fact that some nurseries and kindergartens fail to meet the requirements for disinfection of desktops, faucets and other parts where children are in frequent contact [10-12]. So children are prone to infectious diseases in these institutions. Nesti et al. [13] through the literature review found that the risk of infectious diseases in children in day care or preschool education is two to three times higher than that of ordinary children, and cross-infection may occur in the former. Etiological detection reveals that a variety of pathogens, including bacteria, viruses, mycoplasma, chlamydia can cause AURI. The clinical symptoms of the infection with different pathogens were similar, but there are some significant difference in treatment methods. The effect of the collective life on AURI incidence in preschool children is revealed through the dynamic detection of the aetiology of throat swab, which has an important guiding significance for etiological judgment and clinical treatment.

In this study, there was no significant difference among ages of the first occurrence of AURI, while there was a significant difference between genders. Boys developed AURI for the first time slightly earlier than girls, which was related to personality differences between the genders. Boys were extroverted personality, with a strong desire to explore, so they had more contact with objects. At the same time, boys paid no attention to 
personal hygiene, resulting in higher probability of infectious diseases. The peak time of onset was November, followed by December and September, and the common pathogens were in concentrated distribution. September was the early stage in the nursery, and the temperature fluctuated greatly in November and December, suggesting that external factors were the main cause of AURI in children, and collective life increased the occurrence and cross-transmission of AURI.

In order to avoid the occurrence and cross-transmission of AURI, the following suggestions are provided: (1) the relevant institution should carry out targeted health education for nursery and kindergarten teachers and nursery staffs, and track the absence due to illness and daily morning check of children entering the nursery and kindergarten; (2) regular lectures on health education related to respiratory infectious diseases for children and parents to develop good personal hygiene habits of children; (3) strengthen the environmental hygiene management of nurseries and kindergartens, such as daily and regular ventilation of classrooms and children's rest rooms, weekly mobile ultraviolet disinfection, monthly air culture, and timely treatment of excessive air colony count. In terms of health education, mobile education proposed by Peng et al. [14] can be used for reference, in order to facilitate parental participation and avoid personnel gathering.

According to WHO statistics [15], the main pathogen of respiratory infections in developed countries is viruses, while bacteria are predominant in developing countries. Colonization with pathogens is in the pharynx of children, so one etiological test cannot accurately guide clinical decisions. In recent years, a number of studies reported the causes of AURI in children. Tang et al. [16] found that the virus positive rate was $45.05 \%$, the bacterial positive rate was $10.62 \%$ and the proportion of mixed infection was $18.79 \%$ in 697 AURI cases in the Putuo District, Shanghai. Chi et al. [17] in Taiwan took throat swabs for viral and bacterial culture in 416 children with AURI, and a total of 297 potential pathogens were isolated from 242 patients, with the virus positive rate of $29.6 \%$, the bacterial positive rate of $17.5 \%$, and the mixed infection rate of $11.1 \%$. However, Wang [18] tested nasopharyngeal swabs collected from children with AURI in Shenzhen for respiratory viruses, with the positive rate of $14.55 \%$. There are large differences in the proportion of infections with different pathogens in different regions, but there are a certain proportion of mixed infections.

Cai et al. [19] tested nasopharyngeal samples from 1980 AURI children, and showed that at least one virus detected in $58.13 \%$ of children, while no virus detected in the healthy controls. Homoe et al. [20] studied the pharyngeal pathogen culturing in 70 healthy children and found no colonization with mycoplasma and chlamydia pneumoniae. Hou et al. [21] found that the positive rate of mycoplasma pneumoniae was only $1.47 \%$ after PCR detection of throat swabs in 1906 healthy children. The low carrier rate of non-bacterial pathogens in the pharynx of healthy children and positive results mostly suggest the presence of corresponding pathogen infections. The results of semi-quantitative analysis of throat swabs after onset were compared with the results of physical examination before admission to nursery, and the new $2+$ or more bacterial strains were considered as pathogenic bacteria. In this way, the proportion of bacterial infections in children with AURI could be accurately determined. According to the above criteria, $51.65 \%$ of the 91 children in our study were bacterial infections, and the proportions of mycoplasma and viral infections were $15.38 \%$ and $12.09 \%$, respectively, including 5 (5.50\%) cases of mixed infections of the two bacteria and 5 (5.50\%) cases of mixed infections of bacteria and non-bacterial factors.

In this study, the proportion of AURI bacterial infection in children was higher and the proportion of mixed infection was lower than in other studies, considering the following reasons: climate differences in different regions and seasons: the study was carried out from August to January in a subtropical monsoon climate region, and at this time the temperature conditions were not conducive for virus reproduction; other study data were from large general hospitals or paediatric specialized hospitals, but some parents visited community hospitals or purchased antibiotics for treatment after their children became ill $[22,23]$. And the condition of some children with bacterial infection could be controlled, so there was no need to go to large general hospitals or paediatric specialized hospitals for further diagnosis and treatment, which reduced the proportion of bacterial infections in statistical data.

Twenty-eight children did not develop AURI during the whole semester. There was no significant difference in the number of bacterial strains between the results of pharyngeal swabs at the end of the semester and the results of physical examination. So we speculated that pharyngeal colonization mainly originated from the failure of complete clearance of pathogens after infection, rather than cross-transmission of colonization; or the normal immune function of the human body could clear a small number of cross-transmitted colonization, so the collective life in nursery did not change pharyngeal colonization in healthy children.

\section{Conclusions}

This study found that collective life in nursery caused a concentrated incidence of respiratory infectious diseases in preschool children, which was considered to be related to the cross-transmission of pathogens in the population. Therefore, it is necessary to strengthen the health education of teachers and nursery staffs in nurseries and kindergartens, children and their parents. Bacterial infection is the main cause of AURI in children 
in nurseries and kindergartens, and dynamic etiological detection of throat swabs plays a key role in accurately determining the cause of the disease, which can make it possible to avoid the abuse of antibiotics leading to an increase in bacterial resistance. Because the cases are from the same nursery, with a short time span and a small sample size, this study cannot represent the proportion of infections in the whole population.

\section{Acknowledgments}

Project of Natural Science Foundation of Fujian Province in 2017 (2017j01387).

\section{Conflict of interest}

The authors declare no conflict of interest.

\section{References}

1. Jiang ZF, Shen KL, Shen Y. Zhu Futang Practice of Pediatrics. $8^{\text {th }}$ edition. People's Medical Publishing House, Beijing 2015; 1247-50.

2. Choi WJ, Yim E, Kim TH, et al. Analysis of factors related to the prescription of antibiotics for the acute upper respiratory infection. Health Policy Manag 2015; 25: 256-63.

3. Chen Y, Williams E, Kirk M. Risk factors for acute respiratory infection in the Australian community. PLoS One 2014; 9: e101440.

4. Sun Y, Sundell J. Early daycare attendance increase the risk for respiratory infections and asthma of children. J Asthma 2011; 48: 790-6.

5. Kvćrner KJ, Nafstad P, Jaakkola JJ. Upper respiratory morbidity in preschool children: a cross-sectional study. Arch Otolaryngol Head Neck Surg 2000; 126: 1201-6.

6. Schuez-Havupalo L, Toivonen L, Karppinen S, et al. Daycare attendance and respiratory tract infections: a prospective birth cohort study. BMJ Open 2017; 7: e014635.

7. Kang XL, Zhao ZJ, Li XB, et al. Analysis of 1000 cases of upper respiratory infection in children aged 14-5 years in Beijing. Maternal Child Health Care China 2014; 29: 2039-40.

8. Shang H, Wang YS, Shen ZY. National Clinical Laboratory Procedures. $4^{\text {th }}$ edition. People's Medical Publishing House, Beijing 2015; 637-8.

9. Clinical and Laboratory Standards Institute. Performance standards for antimicrobial susceptibility testing, Fifteenth informational supplement CLSI document: M100-S15. Wayne Pa, USA, CLSI, 2015.

10. Li LJ, Fu NR. Basic Nursing and Technology. $1^{\text {st }}$ edition. China Medical Science Press, Beijing 2017; 398-9.

11. Zhang Y, Yang SP, Wu J, et al. Health care in kindergartens of Wuhan city. Chin I School Health 2016; 37: 41-743.

12. Li EG, Pan XC, Ren H, et al. Effect of disinfection quality in nurseries and kindergartens from 2014 to 2016 in Jing'an District, Shanghai. Shanghai J Prev Med 2018; 30: 769-72.

13. Nesti MM, Goldbaum M. Infectious diseases and daycare and preschool education. J Pediatr 2007; 83: 299-312.

14. Peng CH, Du SS, Zhang YL, et al. Effectiveness of mobile education on parenting behavior and children's health-related behavior. J Nurs Sci 2018; 33: 9-11.

15. World Health Organization (WHO) Indonesia: Health Profile. WHO Media Centre, Geneva, Switzerland 2014.
16. Tang HF, Li XJ, Hu Y, et al. Study on surveillance results of 697 cases of acute upper respiratory tract infection in hospital of Shanghai Putuo District. J Modern Med Health 2020; 36: 47-52.

17. Chi H, Chiu NC, Li WC, et al. Etiology of acute pharyngitis in children: is antibiotic therapy needed? J Microbiol Immunol Infect 2003; 36: 26-30.

18. Wang $H$, Zheng Y, Deng J, et al. Prevalence of respiratory viruses among children hospitalized from respiratory infections in Shenzhen, China. Virol J 2016; 13: 39.

19. Cai XY, Wang Q, Lin GY, et al. Respiratory virus infections among children in South China. J Med Virol 2014; 86: 124955.

20. Homoe P, Prag J, Olsen CB, et al. Nasopharyngeal bacteria found on blood agar plats from healthy children in Greenland. Int J Ciraumpolar Health 1998; 57: 32-9.

21. Hou AC, Liu YH, Xin DL, et al. Nasopharyngeal carriage status of common pathogenic microorganisms in healthy children and its clinical significance. Chin J Pediatr 2002; 40: 45-9.

22. Nathalie E, Giselle S, Ingrid-Katharina W, et al. Pharmacoepidemiology of common colds and upper respiratory tract infections in children and adolescents in Germany. BMC Pharmacol Toxicol 2014; 15: 44.

23. Cao LH. Analysis of oral drug using in children with upper respiratory infection in community. J Pract Gynecol Endocrinol 2017; 4: 9-10. 